\title{
OUTSOURCING DE SERVIÇOS PÚBLICOS HOSPITALARES NA REGIÃO DA GRANDE VITÓRIA/ES
}

\author{
OUTSOURCING OF PUBLIC HOSPITAL SERVICES \\ IN THE REGION OF GRANDE VITÓRIA/ES
}

\section{TERCERIZACIÓN OUTSOURCING DE SERVICIOS PÚBLICOS HOSPITALARIOS EN LA REGIÓN DE LA GRANDE VITÓRIA/ES}

\begin{abstract}
MARCELO MOLL BRANDÃO
Graduação em Administração pela Universidade Federal do Espírito Santo (1996) e mestrado em Ciências Contábeis pela FUCAPE - Fundação Instituto Capixaba de Pesq. em Contabilidade, Economia e Finanças (2006). Doutorando da EAESP/FGV com tese sendo desenvolvida em comportamento do consumidor no varejo (Projeto qualificado em abril de 2010). Pesquisador do Projeto de Estudos sobre Atração dos Pólos Varejistas em SP. Experiência como professor de cursos de graduação, MBA e mestrado. Tem experiência na área de Marketing como pesquisador na produção de artigos científicos, e pesquisas aplicadas para o mercado (consultoria). Tem interesse de pesquisa em comportamento do consumidor, ambiente de loja, qualidade percebida em varejo e serviços, segmentação de mercado, e mensuração de resultados de marketing - Endereço: R. Batataes, 380 apt 73, Jardim Paulista, São Paulo-SP - E-mail: mollmkt@gmail.com
\end{abstract}

\section{JANYLUCE REZENDE GAMA}

Possui mestrado em Contabilidade Gerencial pela FUCAPE - Fundação Instituto Capixaba de Pesquisa em Contabilidade, Economia e Finanças (2006). Atua como professora de Ensino Superior desde 2004. É professora da UFES - Universidade Federal do Espírito Santo. Exerceu suas atividades na STN - Secretaria do Tesouro Nacional (em Brasília) onde participou da $3^{\circ}$ e $4^{\circ}$ edição do MCASP (Manual de Contabilidade Aplicada ao Setor Público). Possui experiência em palestras, cursos e treinamentos na área de contabilidade pública, nas esferas federal, estadual e municipal, em todo país. Instrutora da ABOP (Associação 
Brasileira de Orçamento Público) e da Semana Orçamentária Federal da ESAF. Tem experiência como contadora nas empresas: ECT (Empresa Brasileira de Correios e Telégrafos) e BANDES (Banco de Desenvolvimento do Espírito Santo S.A.). É integrante da Comissão de Contabilidade Pública do CRC ES. Endereço: Av. Fernando Ferrari, 514 - campus universitário, bairro Goiabeiras, Vitória, ES. CEP: 29.075-910. Universidade Federal do Espírito Santo - UFES. CCJE-DCC. E-mail: janylucegama@gmail.com

\section{RESUMO}

Objetiva-se com esta pesquisa analisar e apresentar a terceirização de serviços (outsourcing) como estrutura de governança em hospitais públicos estaduais da Grande Vitória/ES. Utilizou-se de um estudo empírico, no qual foram realizadas pesquisas na Secretaria de Estado da Saúde, Tribunal de Contas do Estado do Espírito Santo e Ministério Público do Trabalho. Foram aplicados questionários em sete hospitais, que foram respondidos pelos responsáveis dos serviços. A pesquisa foi baseada na Economia dos Custos de Transação e procurou estudar a relação de probabilidade de outsourcing com as seguintes variáveis: especificidade do ativo, frequência e incerteza. Os resultados mostraram que os riscos contratuais não são os principais direcionadores da terceirização pública hospitalar, conforme esperado, tampouco a legislação vigente, visto que, pelo baixo enforcement, verificou-se a existência de processos divergentes da lei. Observouse ainda que o administrador hospitalar gerencia pela não existência de falha em áreas críticas, abrindo mão da eficiência de custos de transação. Dessa forma, a falta de recursos por parte do Governo, a ineficiência na contratação de mão de obra pública, bem como a falta de incentivos à performance do agente público, podem levar a situações distantes na organização eficiente da atividade.

Palavras-chave: Hospital Público, Tribunal de Contas, Gestão Hospitalar.

\section{ABSTRACT}

It is the aim of this inquiry to analyze and present the outsourcing of services as a governance framework for the state public hospitals of Grande Vitória/ES. An empirical study was utilized, in which research was conducted along with the State Health Department (Secretaria de Estado da Saúde), the Espirito Santo State Court of Auditors (Tribunal de Contas do Estado do Espirito Santo), and the Ministry of Labor (Ministério Público do Trabalho). Questionnaires were administered to seven hospitals, which were completed by the heads of services. The re- 
search was based on the Economy of Transaction Costs, and attempted to study the probability relation of outsourcing with the following variables: asset specificity, frequency, and uncertainty. As expected, the results show that the contractual risks are not the principal drivers behind the outsourcing of public hospitals, nor is the current legislation, since, due to low enforcement, the existence of processes diverging from the established law were verified. Furthermore, it was observed that the hospital administrator manages toward non-failure in critical areas, setting efficient transaction costs aside. Thus, the lack of government resources, inefficiency in the hiring of public employees, as well as the lack of incentives toward the performance of the government agent, may lead to distant situations in the efficient organization of the activity.

Key-words: Public Hospital; Court of Auditors; Hospital Management.

\section{RESUMEN}

Con esta pesquisa se tiene el objetivo de analizar y presentar la tercerización de servicios (outsourcing) como estructura de gobernanza en hospitales públicos estatales de la Grande Vitória/ES. Fue utilizado un estudio empírico, en el cual fueron realizadas pesquisas junto a la Secretaría de Estado de Salud, Tribunal de Cuentas del Estado de Espírito Santo y Ministerio Público del Trabajo. Fueron aplicados cuestionarios en siete hospitales que fueron respondidos por los responsables de los servicios. La pesquisa fue basada en la Economía de los Costes de Transacción, se procuró estudiar la relación de probabilidades de outsourcing con las siguientes variables: especificidad del activo, frecuencia e incertidumbre. Los resultados mostraron que los riesgos contractuales no son los principales orientadores de la tercerización pública hospitalaria, conforme esperado, tampoco la legislación vigente, visto que, por el bajo enforcement, fue verificada la existencia de procesos divergentes con la ley. Fue observado asimismo que el administrador hospitalario gerencia para que no existan fallos en áreas críticas, renunciando a la eficiencia de costes de transacción. De esa forma, la falta de recursos por parte del gobierno, la ineficiencia en la contratación de mano de obra pública, así como la falta de incentivos a la performance del agente público, pueden llevar a situaciones distantes en la organización eficiente de la actividad.

Palabras clave: Hospital Público; Tribunal de Cuentas; Gestión Hospitalaria.

\section{INTRODUÇÃO}

A terceirização no setor público de saúde tem se colocado como uma alternativa para a flexibilidade da gestão do trabalho, apesar de ser uma opção polêmica. Embora já fosse possível a terceirização na Administração Pública desde 1967 (pelo Decreto-Lei n. 200/67), o 
processo desenvolveu-se de maneira mais rápida na década de 90, após a liberação do Plano Diretor da Reforma do Aparelho do Estado em 1995, ano em que entrou em vigor a implantação da Administração Pública Gerencial, que tem como característica a terceirização das atividades auxiliares e de apoio. Do ponto de vista do serviço prestado, a questão relevante é se tal escolha levará à terceirização dos setores ou funções visando à redução de custos.

A terceirização (ou outsourcing ${ }^{1}$ ) é uma forma na qual organizações públicas realizam a transferência contratual e parcial da responsabilidade pela produção de alguns de seus serviços a empresas privadas. Dessa forma, a decisão de outsourcing, para uma organização privada, estaria vinculada à maximização de lucros, ou ceteris paribus, e à minimização de custos de transação decorrentes dos riscos contratuais (WILLIAMSON, 1985). Para uma organização hospitalar, a legislação vigente, assim como a interpretação dessa legislação pelos mecanismos fiscalizadores e julgadores do Estado, influencia a decisão do administrador público entre contratar um terceiro ou investir em equipamentos, instalações e realizar concursos para aumento de seu efetivo.

Após iniciada a terceirização na área da saúde por intermédio da Lei Municipal n. ${ }^{\circ}$ 11.866/95, do Município de São Paulo, vários outros estados também aderiram à terceirização, com o argumento do aumento da eficiência e da qualidade dos serviços, atendendo melhor o cidadão-cliente a um custo menor (GONÇALVES, 1998).

Contudo, o setor privado, enquanto firma, para o qual grande parte das proposições teóricas de economia de custos de transação foram desenvolvidas, possui objetivos diferentes do setor público, ou seja, não se pode afirmar que os dois setores operam em ambientes similares. $O$ conflito de interesses entre os agentes do setor privado (diretores, administradores e acionistas) envolve a parcela ganha por cada um em um processo de mudança, ou seja, o setor privado está diretamente ligado ao processo pelo qual uma firma transforma os fatores de produção adquiridos em produtos ou serviços para a venda no mercado, com o objetivo de aumentar a lucratividade. Já no setor público, os agentes objetivam melhorar o desempenho, reduzir os custos e obter altos níveis de serviços para melhor servir à população (MCIVOR, 2005).

Considerando, ainda, que o administrador hospitalar se vê limitado pela legislação e pelas consequentes punições em potencial, mesmo que essas não ocorram de forma pecuniária (perda de emprego ou multas), são apresentadas as questões de pesquisa a serem respondidas neste estudo. Os custos de transação gerados pelos riscos contratuais são aceitos em detrimento de perda de serviços em curto prazo? O outsourcing é um arranjo eficiente pelo reduzido custo de transação em comparação à hierarquia, ou surge devido à inviabilidade da hierarquia como único arranjo plausível? E se assim é, isso acontece de forma a impactar tanto os serviços não médicos quanto os serviços médicos, que de início teriam maiores restrições à terceirização?

\footnotetext{
1 O conceito de outsourcing envolve a transferência da fonte dos bens e dos serviços que previamente eram produzidos internamente, dentro da organização, para fonte do fornecedor externo. (MCIVOR 2005, p.7)
} 
Este trabalho tem como objetivo testar a validade das explicações da Economia dos Custos de Transação para o outsourcing no fornecimento de serviços públicos hospitalares. Porém, ressalta-se que o setor público tem propósitos diferentes do setor privado. Isso pode levar a resultados que rejeitam, inicialmente, as hipóteses, mas que podem ser explicados devido ao fato de o setor público estar sempre subordinado à legislação. Assim, ao contrário do setor privado, que pode fazer tudo o que a lei não proíbe, no setor público pode ser feito apenas o que a lei permite, caso exista enforcement suficiente.

Foram incluídos na pesquisa os 7 (sete) hospitais públicos da Grande Vitória, uma base de dados da Secretaria de Estado da Saúde e dados públicos do DATASUS -2006, para a seleção das transações que fizeram parte da amostra.

Na visita aos hospitais e à Secretaria de Estado da Saúde (Sesa) selecionaram-se sessenta e cinco transações de fornecimento de serviços para os sete hospitais, envolvendo arranjos internos e externos. Foram analisados auditorias e processos relativos a terceirizações irregulares na saúde pública existentes no estado, por meio de dados levantados no TCE-ES e MPT. As informações analisadas são relacionadas à alimentação, vigilância, serviços médicos, exames, manutenção em equipamentos médicos, manutenção do prédio, transporte, limpeza e higienização do hospital, serviços de engenharia, laboratório, lactário, serviço de locação de equipamentos, lavanderia e necrotério. Os dados também foram coletados com aplicação de um questionário aos responsáveis por cada setor de serviço estudado, em cada hospital da amostra.

\section{REVISÃO DA LITERATURA}

O conceito de custos de transação pode ser entendido como sendo os custos comparativos de planejar, adaptar e monitorar estruturas de governanças alternativas (WILLIAMSON, 1985). Custos de transação podem ser entendidos como os custos de troca. Essa troca acontece em três passos: primeiro, uma parte da troca tem que ser localizada e isso envolve encontrar alguém que queira comprar o que está sendo vendido, ou vender o que está sendo comprado; segundo, o negócio deve ser acertado entre as partes (um negócio que é alcançado por negociações bem-sucedidas pode incluir o esboço do acordo); terceiro, depois que a negociação sucedeu-se ela deve ser monitorada (o enforcement envolve monitorar a performance das partes e punição à violação do acordo) (COOTER E ULEN, 2003).

Os custos de transação podem ser divididos em custos ex-ante e ex-post. Os custos ex-ante referem-se a dispêndios para negociação, já que nem todas as contingências podem ser previstas, ou seja, são custos preventivos. Já os custos de transação ex-post podem ser considerados como custos de monitoramento e correção.

Existem diversos fatores que podem afetar os custos de transação, como, por exemplo, o tipo de serviços prestados: custos de transação altos para serviços específicos e 
baixos para serviços padrão. O Quadro 1 aborda alguns deles:

\section{Quadro 1 - Fatores que influenciam nos custos de transação}

\begin{tabular}{|l|l|}
\hline \multicolumn{1}{|c|}{ Diminuem os Custos de Transação } & \multicolumn{1}{c|}{ Aumentam os Custos de Transação } \\
\hline 1 - Serviços padronizados & 1 - Serviços exclusivos \\
\hline 2 - Direitos simples e claros & 2 - Direitos complexos e incerteza \\
\hline 3 - Poucas partes & 3 - Muitas partes \\
\hline 4 - Partes amigáveis & 4 - Partes hostis \\
\hline 5 - Partes familiares & 5 - Partes desconhecidas \\
\hline 6 - Comportamento razoável, sensato & 6 - Comportamento insensato \\
\hline 7 - Troca instantânea & 7 - Trocas demoradas \\
\hline 8 - Nenhuma contingência & 8 - Contingências Numerosas \\
\hline 9 - Custos baixos de monitoramento & 9 - Custos altos de monitoramento \\
\hline 10 - Punições baratas & 10 - Punições caras \\
\hline
\end{tabular}

Fonte: Adaptada de Cooter e Ulen (2003).

A Economia dos Custos de Transação de Oliver Williamson aborda a eficiência das transações, vinculada às formas de estrutura de governança. Ainda de acordo com essa teoria, a transação pode ocorrer de duas formas: através do mercado ou por via hierárquica. A ideia básica é a decisão de internalização ou externalização de atividades que são norteadas pela natureza das transações realizadas.

A lógica, segundo a teoria, é a seguinte: as transações econômicas tendem a ser internalizadas, quanto maior for a sua frequência, o grau de incerteza a elas associadas e a especificidade dos ativos nelas envolvidos.

Em ambientes de incertezas, racionalidade limitada e complexidade, os agentes são impulsionados a adotarem iniciativas oportunistas. No caso da literatura econômica, as características dos agentes envolvidos na transação são: oportunismo e racionalidade limitada. O oportunismo é o comportamento de autointeresse do agente, e a racionalidade limitada é a limitação humana no processamento de informações (MCIVOR, 2005).

Como o outsourcing é vulnerável ao oportunismo do fornecedor, cada vez mais a escolha de substituir a integração vertical está sendo mais cuidadosamente observada e analisada, junto com a dimensionalidade mais detalhada das características de governança do mercado, da hierarquia e das formas híbridas (ULSET, 1994).

A racionalidade limitada refere-se à capacidade de armazenamento limitada que o indivíduo possui de receber, armazenar, recuperar e processar informações sem erros. A falta de uma capacidade computacional ilimitada impede o indivíduo de contrair um tipo requerido de teorema padrão na existência de um equilíbrio competitivo (WILLIAMSON, 
1973). Essa característica - racionalidade limitada - determina a incompletude dos contratos, permitindo a exploração de eventuais falhas.

As transações são realizadas entre os agentes econômicos na troca de bens ou serviços. Ao realizarem as trocas, os agentes engajam-se em transações, que se distinguem por três características básicas, que são categorizadas por Williamson (1973) como: incerteza, especificidade do ativo e frequência.

A incerteza é uma característica relevante, já que, quando o nível de incerteza é elevado, é mais fácil para o fornecedor do serviço comportar-se de modo oportuno e fazer com que os contratos sejam mais detalhados (com mais cláusulas para evitar futuros prejuízos), tornando-se mais custosos. Os contratos de longo prazo têm vantagem sobre os de curto prazo porque permitem que as organizações tornem-se mais familiares aos seus fornecedores e capazes de diminuir, assim, o risco do comportamento oportunista. (BARTHELEMY; QUELIN, 2000). Dessa forma, a incerteza pode gerar problemas que podem ser pré-contratuais (seleção adversa) ou pós-contratuais (risco moral).

O risco moral ou moral hazard corresponde ao comportamento de uma pessoa ou agente econômico que, ao receber um determinado tipo de cobertura para suas ações, diminui os cuidados correspondentes a elas. Esse problema tem, então, de ser assumido pelas empresas que fazem essas coberturas, o que faz com que elas aumentem o preço de seus serviços. No caso de seleção adversa, as pessoas e empresas mais prudentes serão prejudicadas pelo aumento no preço dos serviços de cobertura, o que pode afastá-las e resultar em prejuízo ainda maior para as empresas de cobertura. Logo, devido a esses comportamentos, o grau de incerteza impacta diretamente os contratos.

A incerteza provoca a necessidade de atualizar contratos continuamente e incorrer em custos consideráveis de renegociações (POPPO; ZENGER, 1998). Para baixos graus de incerteza, as cláusulas contratuais eficientes podem ser projetadas e o planejamento pode ser executado pelas partes com custos relativamente baixos. Os arranjos baseados em contratos são ainda mais prováveis de serem escolhidos quando os investimentos puderem ser reempregados, mesmo se forem caros (MÉNARD, 2002). As incertezas podem, ainda, estar relacionadas às entradas requeridas por uma transação, às saídas ou aos fatores ambientais.

A incerteza pode também vir dos fornecedores externos, que podem não ter compromisso específico com o arranjo, particularmente, se fornecem as entradas que muitas vezes são mal trabalhadas. Porém, as incertezas na saída são relacionadas aos desajustamentos nas preferências dos consumidores, às dificuldades no controle de qualidade ou às mudanças nas demandas (MÉNARD, 2002).

A frequência pode estar associada ao número de vezes que os agentes realizam determinada transação. A incerteza pode ser entendida como a situação em que os agentes não conseguem prever acontecimentos futuros, ampliando as possibilidades de perdas derivadas do comportamento oportunista das partes. Ativos específicos são aqueles que 
perdem valor quando destinados a outros fins, sendo que sua especificidade pode ser física, temporal, locacional, humana ou dedicada (ZYLBERZSTAJN, 2001).

Quanto maior o nível de especificidade dos ativos, maiores os custos de transação associados à forma de governança via mercado, pois se pressupõe que haja racionalidade limitada e oportunismo por parte dos agentes. De outra parte, estruturas de governança integradas tendem a elevar os custos burocráticos por exigirem a organização em uma única firma, em detrimento da organização independente, via mercado.

Essa ameaça de comportamento oportunista, provocada por recursos específicos, requer caras proteções contratuais. Dessa forma, na presença de ativos específicos, a integração vertical pode oferecer uma solução preferida de governança. Aumentar a especificidade dos recursos da empresa, mais que provocar falhas no mercado, realça a eficiência com que tais atividades são coordenadas pela governança interna (POPPO; ZENGER, 1998). Essas são as características dos custos de transação que explicam a arquitetura dos contratos dentre as características descritas, a especificidade dos ativos é aquela mais destacada pela teoria e de melhor visualização em torno do problema do desenho contratual (ZYLBERZSTAJN, 2001).

Enquanto a Economia dos Custos de Transação tem o propósito de minimizar os custos de transação através das estruturas de governança, a Teoria dos Custos de mensuração se propõe a maximizar o valor da transação, oferecendo garantia para variabilidade do atributo (ZYLBERZSTAJN, 2005). Esses atributos, quando estipulados no contrato, devem ser mensuráveis e verificáveis. Os custos de mensuração podem ser definidos como a dificuldade de mensuração de um determinado atributo, ou dificuldade de saber a qualidade do serviço ex-post, ou mesmo, dificuldade de monitoramento. Neste estudo foi considerado o custo de mensuração como a dificuldade em mensurar a qualidade ex-post do serviço prestado.

Os custos de mensuração, em essência, associam-se às estruturas de governança e à eficiência da transação devido à dificuldade de mensurar determinado atributo na transação. Nesse processo, a firma é vista como um conjunto de garantias ofertadas por um agente especializado, capaz de ofertar salvaguardas, gerando direitos sobre o resíduo (BARZEL, 2002).

Dessa forma, as transações com custos de mensuração baixos podem ser "contratadas" fora da firma, ou seja, podem ser transacionadas no mercado. Elas são amparadas pela lei, uma vez que, no caso de distorções, o adquirente pode acionar o provedor que deve dar garantias para o produto. Já no caso de transações, cujos custos de mensuração são altos, deverão contar com outros mecanismos de garantia que não têm a característica de um contrato. Ou seja, as partes organizam-se privadamente para diminuir os riscos de perda de eficiência na transação, seja pelo desenvolvimento de mecanismos, com base em reputação dos agentes, seja com base em laços sociais, realizando a transação internamente à firma (BARZEL, 2003).

\subsection{Contratos de Outsourcing e Desenvolvimento de Hipóteses}


O outsourcing pode ser definido como uma forma híbrida de governança. O conceito de outsourcing envolve a transferência da fonte dos bens e dos serviços que previamente eram produzidos internamente, dentro da organização, para fonte do fornecedor externo (terceirização). O termo outsourcing pode cobrir muitas áreas, incluindo tanto a fabricação como serviços. É usado, mais comumente, com relação à mudança da fonte do produto ou de atividades do serviço aos fornecedores externos. Pode envolver também a transferência de uma função inteira do negócio a um fornecedor (MCIVOR, 2005, p. 7). A terceirização representa o conceito inverso da integração vertical. Na terceirização, a produção interna é abandonada, destinando sua execução a terceiros, bem como a responsabilidade sobre a execução de algumas etapas.

Os motivos que levam as organizações a terceirizarem algumas etapas são variados. Na saúde pública, por exemplo, a principal questão é a área trabalhista, que, em muitos casos, encontrava-se defasada, lenta e sem treinamento, e encontra-se renovada com melhores profissionais após a terceirização. Outra razão que leva uma empresa ao outsourcing é o aumento da flexibilidade para atender às mudanças do mercado.

Tanto em nível federal quanto estadual, os serviços de saúde pública continuam sendo transferidos à iniciativa privada, sob o argumento de que a gestão ou gerência de unidades hospitalares do estado, por não ser atividade exclusiva, pode ser alocada à iniciativa privada (GONÇALVES, 1998). Serviços que agora são terceirizados antes eram realizados internamente nos hospitais, como arranjo típico hierárquico. Essas mudanças devem-se, entre outras razões, aos baixos salários e problemas trabalhistas: vários funcionários adoeciam ou sofriam acidentes e tinham que ser substituídos por outros durante o período de afastamento e, com isso, acabavam por prejudicar o desempenho das atividades de trabalho.

Desde o Decreto-Lei n. ${ }^{\circ} 200$, de 1967, é permitido, na área da administração governamental, centralizada ou descentralizada, recorrer à execução indireta das atividades públicas de planejamento, coordenação, supervisão e controle, desde que existam empresas privadas desenvolvidas e capacitadas para desempenhar tais atividades. Com a Constituição Federal de 1988, o Art. n. ${ }^{\circ} 197$ permitiu que a execução das ações e serviços de saúde fosse feita tanto diretamente pelo Poder Público como mediante contratação de terceiros, inclusive pessoa física ou jurídica de direito privado, remunerado pelos cofres públicos.

A jurisprudência do Tribunal Superior do Trabalho (TST), em 1980, fixou o enunciado 256, revisto em 1994 pelo enunciado 331, que se tornou referência na área jurídica em relação a fenômenos de terceirização ao tratar da contratação indireta de serviços. Em seu inciso III, autorizou a terceirização quando a admitiu para atividade-meio do tomador. Contudo, a legislação não deixa claro quais seriam as atividades-fim.

Esse inciso incentivou a terceirização para os serviços de vigilância, de conservação 
e limpeza e também para serviços especializados ligados à atividade-meio do tomador, desde que inexistente a pessoalidade e a subordinação direta.

A Lei n. ${ }^{\circ} 8.080$, de 1990 (dispõe sobre as condições para a promoção, proteção e recuperação da saúde, a organização e o funcionamento dos serviços correspondentes, e dá outras providências), diz que a participação complementar será feita quando não houver disponibilidade do Sistema Único de Saúde para a cobertura assistencial à população de uma determinada área.

A administração pública direta e indireta pode contratar serviços de terceiros também amparados nas Leis n. ${ }^{\circ} 8.666 / 93$ (Lei de Licitações e Contratos) e n. ${ }^{\circ}$ 8.883/94 (Lei promulgada em 8 de junho de 1994, que deu nova redação à Lei n. ${ }^{\circ}$ 8.666/93). Em ambas, a contratação de serviços de terceiros, tidas como atividade-meio, é plenamente possível e garantida. Por outro lado, a Lei n. ${ }^{\circ}$ 9.637/98 dispõe sobre a qualificação de entidades como organizações sociais, a criação do Programa Nacional de Publicização e a extinção de cargos no âmbito da administração pública.

O agente atuante na administração hospitalar de uma organização pública pode ser comparado ao mesmo agente em uma instituição privada, se for assumido que, em ambos os casos, existem conflitos de interesse entre ele e seu principal. Se por um lado, em uma organização privada, o principal procura maximizar o lucro, no hospital público essa figura não existe. Nesse caso, o propósito é operar com o máximo de eficácia dentro do orçamento alocado à entidade, e ainda gerir conflitos decorrentes dos atrasos de repasse, procurando não interromper os serviços críticos do hospital.

O agente atuante em um hospital público teoricamente pode ter um conjunto maximizador de utilidade própria que considera apenas os aspectos pecuniários, situação na qual, com salário fixo e relativa estabilidade, teria poucos incentivos a atuar no interesse do bem público. O administrador público é responsabilizado pela contratação, podendo ser acionado judicialmente pelo TCE-ES ou MPT. Por um lado, incentivo para manter o serviço, por outro, incentivo para contratar, se a operação lhe trouxer riscos pessoais. Essa decisão, aqui é classificada em dois extremos: integração vertical e outsourcing (MCIVOR, 2005).

A contratação de terceiros é um arranjo superior à contratação via CLT, pois é concretizado mais rapidamente, sem necessidade de concurso público para contratação de mão de obra, possuindo maior incentivo ao agente privado, pois o contrato pode não ser renovado. Os recursos não são distribuídos igualmente para decisão de contratar funcionários, adquirir equipamentos para o hospital ou contratar o serviço. Os procedimentos para contratação de pessoal e aquisição de equipamentos envolvem maior burocracia, se comparados com licitações.

Assim, espera-se que o impacto dos custos de transação, segundo os riscos contratuais de especificidade de ativo, custo de mensuração e impacto econômico da falha, não sejam tão representativos para hospitais públicos quanto para a iniciativa privada. 
As transações com custos de mensuração baixos podem ser contratadas fora da firma. Já no caso de transações, cujo custo de mensuração seja mais difícil, as partes organizam-se privadamente para diminuir os riscos de perda de eficiência na transação, realizando a transação internamente à firma (BARZEL, 2003).

A dificuldade de mensurar a qualidade dos serviços prestados em um hospital varia de acordo com cada serviço. Alguns serviços, como limpeza ou restaurante, por exemplo, podem ter sua qualidade testada enquanto outras, como cirurgias, não têm o mesmo grau de facilidade para visualizar a qualidade do que foi realizado. Diante do exposto, apresentase a hipótese de pesquisa: h1: A probabilidade de outsourcing é negativamente relacionada com custos de mensuração.

A segunda hipótese de pesquisa refere-se ao impacto econômico da falha que intensifica, em uma condição de incerteza e custos de mensuração elevados, a probabilidade de integração vertical (AQUINO, 2005). O impacto econômico gerado pela falha do profissional na área hospitalar pode gerar, desde um simples retrabalho até a paralisação das atividades do hospital ou a morte de um paciente. Assim, apresenta-se a segunda hipótese: h2: A probabilidade de outsourcing é negativamente relacionada com o impacto econômico da falha.

A terceira hipótese de pesquisa se refere a quando um serviço é muito específico; ele não pode ser transferido ou reposto para usos alternativos, sem perda do valor produtivo. Assim, quanto mais específico for o serviço, mais custosa será a sua realocação para outra atividade. A especificidade aqui trabalhada foi desdobrada em humana e dedicada. A especificidade de capital humano no hospital está associada ao conhecimento acumulado pelos profissionais em determinadas atividades, cuja aplicabilidade em outras atividades é limitada. Assim, os serviços médicos são mais específicos, já que o conhecimento na área carece de muito estudo e treinamento especializado.

A especificidade de ativos dedicados é a realização de investimentos para atender especificamente a um cliente. No caso dos hospitais, os equipamentos médicos são específicos para determinados exames, não podendo ser realocados para outras atividades. Portanto, espera-se maior especificidade de ativos para atividades-fim, o que levaria à opção de manter esses serviços internos no hospital. Assim, apresenta-se a terceira hipótese: h3: A probabilidade de outsourcing é negativamente relacionada com a especificidade do serviço.

A quarta hipótese a ser testada está relacionada à incerteza. Essa modalidade de licitação oferece maior risco ao agente público, decorrente da não observância da reputação do fornecedor no mercado, não sendo contratado assim o agente privado pela sua eficiência, e sim pelo baixo custo cobrado por seus serviços. Quanto maior a incerteza, menor a probabilidade de terceirização. Portanto, espera-se encontrar que os serviços médicos, por serem atividades de risco, não sejam terceirizados. Assim, apresenta-se a quarta hipótese: h4: A probabilidade de outsourcing é negativamente relacionada com a incerteza da transação. 
A quinta hipótese está relacionada à recursividade. A recorrência na prestação dos serviços realizados nos hospitais varia de acordo com cada atividade. Transações pouco frequentes com baixo grau de incerteza e especificidade levam a estrutura de governança para o mercado. Quanto maior a recursividade, ceteris paribus, maior a probabilidade de organizá-la internamente: h5: A probabilidade de outsourcing é negativamente relacionada com a recursividade.

\section{MODELO DE REGRESSÃO E VARIÁVEIS ESTUDADAS}

Esta pesquisa teórico-empírica utilizou, para testar as suas hipóteses, dados obtidos a partir de análise de documentos dos hospitais da GV, informações de banco de dados público referentes aos serviços em questão e questionário aplicado aos gestores dos hospitais. Como método para testar as cinco hipóteses do estudo, foi utilizado um modelo de regressão multivariada (Logit), que permite mensurar de forma robusta a associação entre variáveis independentes e uma dependente que tenha sua variação em probabilidade de ocorrência de um evento específico.

O modelo de regressão utilizado tem como variável dependente a probabilidade de outsourcing (PROB(OUT)) e como variáveis independentes: o custo de mensuração (CM), o impacto econômico da falha (IE); a especificidade do serviço (K); a incerteza (INC); e a recursividade (REC). Serão controlados: o porte do hospital (PORTE); o tipo de serviço (SERV); a natureza jurídica (NAT); e o hospital (HOSP).

\subsection{Variáveis Dependentes}

A variável dependente utilizada na pesquisa, foi Probabilidade de outsourcing PROB(OUT). Para obter os valores que fariam parte da base de dados dessa variável, foram separados os serviços em insourcing e outsourcing. A relação dos contratos terceirizados foi fornecida pela Secretaria de Saúde do Estado, e a relação dos serviços realizados internamente nos hospitais foram coletados através da base de dados do Ministério da Saúde - (Datasus).

Essa variável foi inserida na pesquisa como dicotômica, sendo que PROB(OUT) assume valor 0 (zero) para os serviços considerados insourcing, e 1 (um) para outsourcing.

\subsubsection{Variáveis Independentes}

Os vários tipos de serviços que compõem a amostra para essa pesquisa comportam diferentes graus de dificuldade para avaliar a qualidade do serviço ex-post nos hospitais (CM). Para mensurar se os serviços selecionados contemplam alto ou baixo grau dessa variável, utilizou-se escala Likert de cinco pontos: discordo totalmente (1) a concordo totalmente (5). A confiabilidade da medida apresentou um Alfa de Cronbach $=0,94$, revelando que os indicadores de constructos são confiáveis.

No questionário, as questões que mediram a variável CM foram: 
CM1 - A qualidade do serviço prestado pode ser analisada visualmente;

CM2 - O hospital precisa disponibilizar profissionais qualificados internos para avaliar a qualidade do serviço prestado;

CM3 - O hospital possui resposta imediata (no mesmo dia) do serviço mal realizado.

\section{RESULTADOS DO TESTE DE VALIDAÇÃO CONVERGENTE DAS VARIÁVEIS}

O resultado do teste de validade convergente indicou que o conjunto das medidas adotadas para a variável $\mathrm{CM}$, representa, com precisão, o conceito de interesse, como mostra a Tabela 1. Para o teste de correlação das variáveis independentes, foi realizada a correlação de Spearman, que serve para testar dados não paramétricos. Após observar alta correlação entre as medidas da variável $\mathrm{CM}$, ela foi reduzida a um fator, por meio de uma matriz de correlação, que obteve cargas fatoriais entre 0,912 e 0,966. O teste da análise fatorial foi considerado significante, através do teste das comunalidades com resultados entre 0,831 e 0,933, e confirmado pelo critério de percentagem de variância com um percentual cumulativo de $88,78 \%$.

O impacto econômico da falha do profissional (IE) em um hospital pode ir de um simples retrabalho à possibilidade de paralisação das atividades, com um alto grau de consequência da falha cometida. $O$ grau desse impacto também foi mensurado através da escala Likert. A confiabilidade da medida apresentou um Alfa de Cronbach $=0,74$, demonstrando que os indicadores de constructos também são confiáveis.

IE1 - A falha cometida pelo profissional terceirizado gera consequências graves e prejudica a imagem do hospital frente à sociedade;

IE2 - A ocorrência da falha por parte do profissional terceirizado gera sanções internas para os funcionários externos;

IE3 - Falhas cometidas por profissionais dessa área geram apenas um simples retrabalho, não prejudicando os pacientes do hospital;

IE4 - A falha ocorrida nesse tipo de serviço interrompe imediatamente outro tipo de serviço do hospital;

IE5 - As falhas cometidas pelos profissionais terceirizados que supervisiono afetam-me, negativamente, como profissional do hospital;

IE6 - As falhas cometidas por esses profissionais geram risco de morte aos pacientes.

O resultado do teste de validade convergente indicou que o conjunto das medidas adotadas para a variável IE apresentava problemas de baixa correlação (menor que o limite de 0,30 ) entre as medidas IE1 e IE2. Para que o problema fosse solucionado, foi realizada uma pesquisa aprofundada nas medidas, por meio da qual foi constatado que, por força 
de lei (Lei n. ${ }^{\circ}$ 8.666/96, Art. 58, IV), a modalidade de coerção contida na questão IE2 era obrigatória. Por essa razão, retirou-se a questão da amostra.

IE3 foi retirada após a análise das comunalidades, pois apresentou resultado $(0,116)$ muito abaixo do esperado, além de uma carga negativa no fator extraído da análise fatorial. Restando assim 4 (quatro) medidas.

No teste de Análise Fatorial, as cargas dos fatores variaram entre 0,682 e 0,828. 0 resultado do teste foi considerado satisfatório. Porém, por meio da análise das comunalidades, percebeu-se que o fator gerado não se mostrava altamente significante, uma vez que a variância de algumas medidas originais compartilhadas com outras variáveis incluídas na análise não obedece ao limite de 0,60, variando entre 0,41 e 0,71. Esse resultado pode ser comprovado também através do critério de percentagem de variância, que obteve como resultado do percentual cumulativo apenas $55,92 \%$, resultado menor que o limite esperado de $60 \%$. Porém, o resultado foi considerado válido por tratar-se de uma pesquisa na área de ciências sociais, nas quais as informações, geralmente, são menos precisas, e uma solução que explique menos de $60 \%$ da variância total pode ser considerada satisfatória (HAIR et al., 2005).

Outras variáveis que fizeram parte da pesquisa foram as características das transações: especificidade do serviço, incerteza externa e recursividade. A especificidade dos serviços prestados foi desdobrada em: especificidade de capital humano - teve como proxy a dificuldade de realocação do contrato para outras atividades; e especificidade de equipamentos - tempo gasto para reintegrar a atividade terceirizada e a realocação de equipamentos específicos utilizados nos serviços hospitalares.

Essas especificidades foram mensuradas através da escala Likert, assim como as outras variáveis independentes. A confiabilidade da medida apresentou um Alfa de Cronba ch $=0,741$, demonstrando que os indicadores de constructos são confiáveis. Foram representadas no questionário por meio das questões:

K1 - Tenho dificuldade em realocar esses profissionais para outras atividades;

K2 - Tenho dificuldade de encontrar outros profissionais no mercado para substituir o fornecedor;

K3 - Tenho dificuldade de realocar os equipamentos utilizados por esses profissionais por serem equipamentos específicos para o tipo de serviço.

O resultado do teste de validade convergente indicou que o conjunto das medidas adotadas para a variável K representa com precisão o conceito de interesse, estando acima do limite esperado de 0,30.

Após observar a correlação entre as medidas da variável $\mathrm{K}$, ela também foi reduzida a um fator, que obteve cargas fatoriais entre 0,782 e 0,874. O teste da análise fatorial foi 
considerado significante através do teste das comunalidades, com resultados entre 0,581 e 0,764 e confirmado pelo critério de percentagem de variância, com um percentual cumulativo de $66,05 \%$.

A incerteza (INC) nas transações com os fornecedores terceirizados também foi testada. Devido ao fato de o processo de contratação passar pela licitação, o qual se vence pela técnica e menor preço, esperava-se que essa variável apresentasse alto grau de incerteza para grande parte dos serviços. Essa variável também foi mensurada por intermédio da escala Likert, e apresentou, como resultado da confiabilidade da medida, um Alfa de Cronbach $=0,758$, indicando que os constructos também são confiáveis. Esse teste foi refeito após a retirada das medidas INC3 e INC4. O primeiro teste havia apresentado um resultado de 0,616, registrando baixa consistência interna.

A retirada das proxies de incerteza INC3 e INC4 foram feitas devido ao fato de apresentarem correlações negativas com as demais e cargas negativas nos fatores. Após um estudo aprofundado nessas variáveis, percebeu-se que elas não estavam medindo apenas incerteza da transação, podendo estar ligadas a outros conceitos da teoria (o que prejudicaria a validade discriminante) e dar a entender que:

INC3 - além de ser procedimento obrigatório do hospital, para todos os tipos de serviços (Lei n. ${ }^{\circ}$ 8.666/96, Art. n. ${ }^{\circ} 67$ ), pode medir também mecanismo de ordenamento privado; e

INC4- a reputação do fornecedor não está ligada apenas à incerteza, mas também ao impacto econômico da falha e especificidade do serviço.

No questionário, a variável foi representada pelas questões:

INC1 - Tenho dificuldade de avaliar a necessidade futura do hospital para este serviço, no que diz respeito à tecnologia;

INC2 - Tenho dificuldade de avaliar a necessidade futura do hospital para este serviço, no que diz respeito à competência humana;

INC3 - Esse serviço deve ser monitorado por funcionários do hospital sempre que realizado;

INC4 - Antes de contratar um serviço, sempre procuro conhecer a reputação da empresa em questão.

O resultado do teste de validade convergente, entre as proxies INC1 e INC2, apresentou um valor de 0,593 , o que indica ser um resultado satisfatório. $A$ análise fatorial apresentou um fator com carga de 0,902, o que indica um resultado bastante significante, indicado pela análise das comunalidades com resultado de 0,814 , e pelo critério de percentagem da variância, com resultado de $81,38 \%$.

A recursividade foi a última variável independente mensurada no questionário. Essa variável representa a freqüência com que os serviços são realizados no hospital. A escala 
Likert usada para essa medida foi: 5 para serviços realizados diariamente; 4 , semanalmente; 3 , quinzenalmente; 2 , mensalmente; e 1, outros.

Para testar a multicolinearidade entre os fatores gerados pelas variáveis independentes, foi realizado o teste da validade discriminante, que indica que as medidas, mesmo semelhantes, são conceitualmente distintas, pois as correlações entre os fatores, mesmo significantes, foram consideradas pequenas para a amostra.

\subsection{Variáveis de Controle}

A variável "Hospital" (HOSP) assume valores de 1 a 7, de acordo com a participação de cada instituição na amostra, referente às 65 transações utilizadas, entre serviços internos e terceirizados. A variável "tipo de serviço" (SERV) foi separada entre serviços médicos ou atividades-fim e serviços não médicos ou atividades-meio, assumindo valores de 1 (um) para os serviços médicos e zero para os serviços não médicos. A variável "natureza jurídica" (NAT) foi separada em Administração Direta e Administração Indireta. Essa variável assumiu valores de 0 (zero) para as instituições ligadas diretamente à Secretaria da Saúde e 1 (um) para as Autarquias. A variável "Porte dos Hospitais" (PORTE) foi classificada de acordo com o número de leitos, sendo de pequeno porte os que possuem até 50 leitos; de médio porte, de 51 a 150 leitos; e de grande porte, acima de 150 leitos. Os valores atribuídos foram: 1 (um) para os considerados de grande porte; 2 (dois) médio porte; e 3 (três) pequeno porte.

Para verificar a possibilidade de existência de multicolinearidade, após a inclusão das variáveis de controle, foi realizado o teste de Fator de Inflação da Variância (VIF) (HAIR et al., 2005). Um VIF acima de 10 (equivalente a uma tolerância abaixo de 0,10) exprime uma colinearidade alta. Porém, neste estudo, nenhum VIF ultrapassou o valor 10 (o maior valor obtido é 3,343). Portanto, a multicolinearidade é de grau baixo, não causando distorção que comprometa os resultados.

\subsection{Dados}

A presente pesquisa foi realizada nos hospitais públicos estaduais da Grande Vitória/ ES. Trabalhou-se com toda a população proposta : 7 (sete) hospitais públicos estaduais.

Para a coleta de dados, foram realizadas, ainda, pesquisas na Secretaria de Estado da Saúde (Sesa), no Tribunal de Contas do Estado do Espírito Santo (TCE-ES) e no Ministério Público do Trabalho (MPT) - $17^{\text {a }}$ Região/ES.

$\mathrm{Na}$ Secretaria de Saúde Pública Estadual foram selecionados contratos de serviços terceirizados referentes aos anos de 2004 e 2005. Quanto aos serviços internos, a seleção foi realizada através da base de dados do Ministério da Saúde (Datasus), com a proposta de analisar o alinhamento ou desalinhamento dos arranjos reais com os previstos pela Economia dos Custos de Transação. 
A primeira etapa da pesquisa teve início com a visita aos hospitais (a fim de conhecer o ambiente institucional) e à Sesa, onde foram selecionadas sessenta e cinco transações de fornecimento de serviços para os sete hospitais, envolvendo arranjos internos e externos. Entre as transações, encontram-se alimentação, vigilância, serviços médicos, exames, manutenção em equipamentos médicos, manutenção do prédio, transporte, limpeza e higienização do hospital, serviços de engenharia, laboratório, lactário, serviço de locação de equipamentos, lavanderia e necrotério.

Foram analisados ainda as auditorias e processos relativos a terceirizações irregulares na saúde pública existentes no estado, através de dados levantados no TCE-ES (período de 2003-2006) e MPT (período de 2002-2006).

A segunda etapa consistiu na escolha das proxies (detalhadas no Capítulo 3) que foram baseadas (incerteza) no estudo de Barthelemy e Quelin (2000) e (custo de mensuração) no estudo de Aquino (2005).

Na terceira etapa, foram coletados dados por meio da aplicação de um questionário aos responsáveis por cada setor de serviço estudado, em cada hospital da amostra.

Para a aplicação do questionário, foi utilizada a escala Likert, de cinco pontos com alternativas (concordo totalmente; concordo parcialmente; indiferente; discordo parcialmente; discordo totalmente). Cada uma das alternativas foi pontuada de 1 a 5 , de maneira que a primeira (concordo totalmente) equivale ao ponto máximo da variável testada (5) e a última (discordo totalmente) recebe a pontuação mínima (1), equivalendo ao ponto em que a medida da variável está mais baixa. Foram atribuídos os valores correspondentes às respostas do questionário aplicado.

Após a aplicação dos questionários para a coleta de dados, foi testada a confiabilidade da escala analisada por meio do alfa de Cronbach $^{2}$, que é uma técnica utilizada quando a resposta ao item pode assumir mais de duas alternativas. Seu resultado é um indicador sumário da consistência interna da escala analisada e, consequentemente, dos itens que a compõem. A vantagem da utilização dessa técnica é a possibilidade de se obter uma medida tão confiável e tão válida quanto possível, utilizando o menor número de itens, isto é, selecionar itens que contribuam ao máximo para a confiabilidade e validade (COOPER, 2003).

Este estudo contou ainda com testes de validade. A validade é o grau em que uma escala ou conjunto de medidas representa o conceito de interesse. $O$ teste de correlação inter-itens atende à validade convergente (que avalia o grau em que duas medidas do mesmo conceito estão correlacionadas. Assim, correlações altas indicam que a escala está medindo seu conceito pretendido) e à validade discriminante (é o grau em que dois conceitos similares são distintos). Nesse caso, a correlação deve ser baixa, demonstrando que a escala múltipla é suficientemente diferente do outro conceito semelhante (HAIR, 2005).

\footnotetext{
${ }^{2}$ Limitações do teste: não deve ser usado para respostas homogêneas, já que o teste é feito para amostras multidimensionais (SCHMITT, 1996). Não deve ser usado nos casos em que as respostas resultem em zero ou um; nesses casos, é melhor utilizar o "K-R Formula 20" (SHAVELSON, 2004). Não existe nível ideal para aceitação ou não aceitação no teste do alfa de Cronbach (PETERSON,1994).
} 
Por fim, foram realizados testes de análise fatorial (que é o modelo no qual os fatores são baseados em uma matriz de correlação reduzida) juntamente com a análise das comunalidades (que ajuda a identificar os itens pobres dos fatores) e a análise de percentagem de variâncias (que é uma abordagem baseada na conquista de um percentual cumulativo especificado da variância total extraída dos fatores).

Finalmente, utilizou-se de uma regressão logística, uma vez que a variável dependente é dicotômica. Para o teste de regressão, somente foram utilizadas 65 transações, eliminando repetições constantes de respostas nos serviços médicos e exames.

\section{ANÁLISE DOS RESULTADOS}

Conforme se pode observar na Tabela 1, na primeira das três equações, foi inserida a variável K1 (especificidade de capital humano); na segunda, foi utilizada a variável K2 (especificidade de equipamentos); e, na terceira, K1_2, que é a combinação das duas variáveis anteriores. Todas as equações foram controladas pelas variáveis: hospital, tipo de natureza jurídica (administração direta e indireta), tipo de serviço (médico e não médico) e porte do hospital (pequeno, médio e grande).

Tabela 1: Resumo dos testes de regressão

VARIÁVEL DEPENDENTE - Probabilidade de Outsourcing - PROB(OUT)

\begin{tabular}{|l|c|c|c|}
\hline \multicolumn{4}{|c|}{ MODELO DE REGRESSÃO - Logit } \\
\hline $\boldsymbol{\beta}$ REGRESSÃO & 1 & 2 & 3 \\
\hline $\boldsymbol{\beta}$ IE & 0.174 & 0.146 & 0.145 \\
\hline $\boldsymbol{\beta}$ K1 & 0.269 & 0.259 & 0.374 \\
\hline $\boldsymbol{\beta}$ K2 & -0.238 & - & -0.156 \\
\hline $\boldsymbol{\beta}$ INC & - & 0.449 & 0.435 \\
\hline $\boldsymbol{\beta}$ REC & $-1.077^{* *}$ & $-1.115^{* *}$ & -1.156 ** \\
\hline Y NAT & 0.007 & -0.163 & -0.130 \\
\hline Y HOSP & -0.080 & -0.193 & -0.148 \\
\hline Y PORTE & -0.022 & 0.026 & 0.022 \\
\hline Y SERV & -0.533 & -0.580 & -0.590 \\
\hline B0 & 1.234 & $1.483 *$ & $1.509 *$ \\
\hline McFadden R-squared & 1.229 & 1.389 & 0.310 \\
\hline LR statistic & 0,137 & 0,154 & 0,156 \\
\hline
\end{tabular}




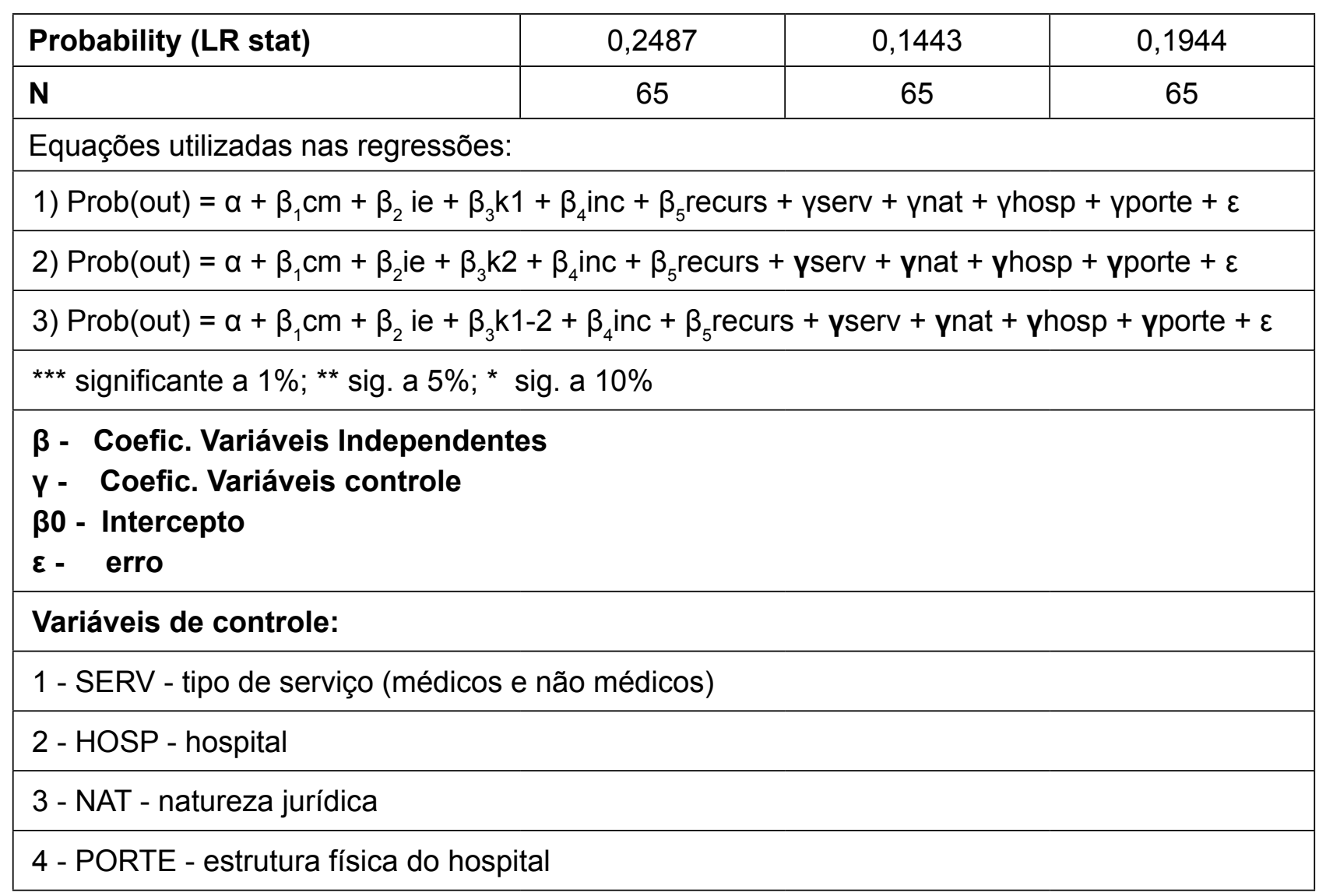

Fonte: elaborado pelos autores.

Pode-se verificar que o modelo apresentado não tem significância estatística, ou seja, não tem validade de explicação. Assim, pode-se entender que a Economia dos Custos de Transação não explica a terceirização na área da saúde (Tabela 1).

Portanto, a administração pública depende de outros fatores que não são explicados pela teoria. Esses fatores foram analisados através das pesquisas realizadas no TCE-ES e no MPU. Entre eles, podem-se citar a redução das despesas públicas e a melhora dos serviços prestados a sociedade (Tabela 1).

Conforme Tabela 1, segundo a legislação, para se obter uma terceirização lícita, é necessário definir os tipos de serviços (SERV) em atividades-meio e fim na forma da missão, pois só poderá contratar serviços para a área-meio. Já as contratações que sejam para a área-fim do órgão não são procedimentos corretos, portanto, combatidas pelo Ministério Público do Trabalho e pelos órgãos de controle, sendo firmados acordos com cronograma de substituição dessa mão de obra por servidores concursados.

Por meio dos testes, pode-se verificar ainda que, das hipóteses testadas, nenhuma pode ser explicada pela Teoria dos Custos de Transação. Esperava-se encontrar uma relação negativa entre essas variáveis e a probabilidade de outsourcing. Porém, no resultado encontrado no setor público de saúde estadual, nenhuma das variáveis interfere na escolha da terceirização (Tabela 1). Esse resultado pode ser explicado devido ao fato de que, no se- 
tor público de saúde, todos os serviços, independente do grau de importância ou dificuldade e do porte do hospital, ou se fazem parte da administração direta ou indireta, estão sendo submetidos ao mesmo processo de terceirização baseados na mesma legislação.

A explicação para o fato de a teoria não se aplicar ao setor público é que a escolha de terceirizar determinadas atividades não está ligada ao aumento de lucratividade ou mesmo à vantagem competitiva, como no setor privado. O setor público está ligado diretamente a restrições legais impostas ao administrador hospitalar.

Porém, a maior diferença entre os setores público e privado, na escolha pela terceirização, confirmadas na pesquisa no MPU, é que no setor público, de acordo com o Princípio da Legalidade, as decisões são tomadas em prol da legislação e não inclui certas atividades das contratações internas. Essa política de redução dos quadros de mão de obra que o estado vem adotando está apoiada na redução das despesas públicas. Já no setor privado, a decisão tomada pelos agentes não conflita com leis e decretos, mas toma uma forma de vantagem competitiva diante do mercado.

Assim, devido à legislação própria para o setor público, não seria possível encontrar resultados semelhantes nos dois setores, quando aplicados à mesma teoria. É importante ressaltar ainda que o ambiente institucional público, a partir da década de 90, vem sendo modelado para esse tipo de arranjo (terceirizado), com base da legislação citada.

\section{CONCLUSÃO}

No modelo proposto, verificou-se, por meio das regressões, que nenhuma hipótese pode ser explicada, já que o modelo não apresenta significância estatística. Observou-se que, no setor público, a Economia dos Custos de Transação, apenas, não explica o processo de terceirização. Isso sugere que podem existir outros fatores que exercem maior influência do que os riscos contratuais envolvidos. Observou-se ainda que os efeitos de perda de eficiência da organização hierárquica podem ser também os principais direcionadores do movimento de outsourcing, visto que serviços médicos e não médicos respondem, da mesma forma, à falta de explicação do modelo.

As irregularidades identificadas apontam para um movimento de outsourcing que vai além do permitido, ou seja, os administradores hospitalares assumem o risco e partem para o outsourcing, mesmo em serviços de difícil mensuração, como os médicos, por meio de relações híbridas com cooperativas médicas. Isso pode ser um efeito da falta de recursos internos, assim como da burocracia envolvida em um processo de contratação via concurso.

Por fim, não se pode reduzir simplesmente a explicação à questão da legislação, pois o enforcement não é pleno e as terceirizações são feitas mesmo nas situações não previstas. As restrições de recursos internas ao hospital e urgência da resolução de falhas em serviços, principalmente em áreas críticas, podem fazer o administrador não considerar 
todo impacto econômico de eficiência e economicidade para atender à eficácia, mesmo que, para isso, tenha de divergir da legislação e escolher um arranjo não eficiente em termos de custo de transação.

Portanto, a falta de recursos por parte do Governo (atraso no repasse de recursos, orçamentos insuficientes para reposição dos equipamentos e instalações), a ineficiência na contratação de mão de obra pública (burocracias dos concursos, seleção adversa, equiparação salarial), bem como falta de incentivos à performance do agente público (salários fixos, estabilidade de emprego) podem levar a situações distantes na organização eficiente da atividade, à medida que o hospital se terceiriza.

Esta pesquisa limitou-se ao estudo do Princípio da Legalidade, porém sabe-se que a Constituição Federal de 88, em seu Art. 37, trata de outros princípios norteadores não menos importantes para a administração pública. A pesquisa pode ser ampliada com a criação de proxies que proporcionem testar estatisticamente princípios como economicidade, eficiência, eficácia.

Esta pesquisa apresenta ainda como limite a região da Grande Vitória, pois as evidências de irregularidades (falta de enforcement), assim como a atuação do TCE, e escoIhas feitas podem não ser similares a outras administrações públicas hospitalares no Brasil. Devido à restrição de tempo e acesso aos dados, esta pesquisa não pode ser mais ampla e profunda, porém a discussão sobre este assunto poderia evoluir com a melhoria de proxies, ampliação e aprofundamento por meio do aumento da amostra para hospitais de todo o estado, região e país, controlando as diferenças regionais e estados, e ainda, controlando as permissões da legislação quanto ao tipo específico de atividade. Outros controles, no caso de uma pesquisa com amostra mais ampla, devem ser as restrições orçamentárias, atrasos de repasses de verbas e dificuldades na reposição de mão de obra dos hospitais.

\section{REFERÊNCIAS}

AQUINO, André Carlos Busanelli de. Economia dos arranjos híbridos: o caso da coordenação de serviços em uma usina siderúrgica. 2002. 217 f. Tese (Doutorado em Ciências Contábeis) - Faculdade de Economia, Administração e Contabilidade, Universidade de São Paulo (USP), São Paulo, 2005.

BRASIL MINISTÉRIO DA SAÚDE. Base de dados. Disponível em: <http: www.ministeriodasaude.gov.br>. Acesso em 14/11/2006.

BARTHELEMY, Jerome; QUELIN, Bertrand V. Contractual agreements and outsourcing: a transaction analysis. Annual Conference of International Society for New Institutional Economics, p. 22-24, set. 2000. 
BARZEL, Yoram. Organizational forms and measurement costs. International society for new institutional economics, ago., 12, 2002. Disponível em: <http:www.isnie.org/ISNIE02/ Papers02/barzel.pdf>. Acesso em 15/08/2005.

BARZEL, Yoram. Standards and the form of agreement. International society for new institutional economics, jul. 2003. Disponível em: www.isnie.org/ISNIE02/Papers04/barzel.pdf Acesso em 15/08/2005.

BRASIL. Constituição Federal de 1988. Disponível em: <www.planalto.gov.br/Constituicao>. Acesso em: 15 nov. 2006.

Ministério Público do Trabalho - $17^{\circ}$ Região. Ação de Execução de Termo de Ajustamento e Conduta em face do IESP. AE 710.2005.005.17.00. Documento disponível para Consulta Pública. Ministério Público do Trabalho - $17^{\circ}$ Região.

Lei N. ${ }^{\circ} 8.080$ de 1990. Disponível em: <www.cff.org.br>. Acesso em: 15 nov.2006.

. Lei N. ${ }^{\circ} 8.666$ de 1993. Disponível em: <www.planalto.gov.br/ccivil/Leis/L8666cons. htm>. Acesso em: 15 nov. 2006.

. Lei N. • 8.142/1990. Disponível em: <www.conselho.saude.gov.br/legislacao/ lei8142_281290.htm>. Acesso em: 26 nov. 2006.

. Lei N. ${ }^{\circ} 101 / 2000$. Lei da Responsabilidade Fiscal. Disponível em:<www.tesouro.fazenda.gov.br/hp/downloads/lei_responsabilidade/lc101_2000.pdf>. Acesso em: 28 nov. 2006.

Decreto Lei $\mathbf{n} .^{\circ} 200$ de 1967. Disponível em: <www.planalto.gov.br/ccivil/DecretoLei/Del0200>. Acesso em: 15 nov. 2006.

Tribunal Superior do Trabalho (TST). Enunciado $n .{ }^{0} 331$ de 1994 -Disponível em: <www. dji.com.br/normas_inferiores/enunciado_tst/tst_0331a0360.htm>. Acesso em: 15 nov. 2006.

COOPER, Donald R.; SCHINDLER, Pámela S. Métodos de pesquisa em administração. 7. ed. Porto Alegre: Bookman, 2003.

COOTER, Robert; ULEN, Thomas. Law and economics. 4. ed. Reading, MA: AddisonWesley, 2003. 
CRONBACH, Lee J., SHAVELSON, Richard J. My current thoughts on coefficient alpha and successor procedures. Working paper, Center for the Study of Evaluation (CSE) Educational and Psychological Measurement, 64, p. 391-418. jun. 2004.

GONÇALVES, Wagner. Parecer sobre terceirização e parcerias na saúde pública. Conferência Nacional de Saúde On-Line. Maio, Brasília: 1998. Disponível em: <http://www. datasus.gov.br/cns>. Acesso em: 22 dez. 2005.

HAIR, J. et al. Análise multivariada de dados. 5. ed. Porto Alegre: Bookman, 2005.

MCIVOR, Renan. The outsourcing process: strategies for evaluations and management. New York: Cambridge University Press. 2005.

MÉNARD, Claude. The economics of hybrid organizations. Journal of Institutional and Theoretical Economics, set. 2002. Disponível em: <2004.atom.univ-paris1.fr/documents/ Menard_JITE_2004.pdf>. Acesso em: 20 ago. 2006.

POPPO, Laura; ZENGER, Todd. Testing alternative theories of the firm: transaction cost, knowledge-based, and measurement explanations for make-or-buy decisions in information services. Strategic Management Journal, v. 19, n. 19, p. 853-877, 1998.

ULSET, Svein. R\&D outsourcing and contractual governance: an empirical study of commercial R\&D projects. Journal of Economic Behavior \& Organization, v. 30, n. 1, p. 63-82, dez. 1994.

VIEIRA, Antonieta Pereira et al. Gestão de contratos de terceirização na administração pública. Belo Horizonte: Editora fórum, 2006.

WILLIAMSON, Oliver E. Markets and hierarchies: some elementary considerations. The American Economic Review, v. 63, n. 2, Papers and Proceedings the eighty-fifth annual meeting of American Economic Association, may: 1973. Disponível em: <www.jstor.org>. Acesso em: 05 jan. 2006

. The economic institutions of capitalism: firms, markets, relational contracting. New York: Free Press, 1985.

. The institutions of governance. The American Economic Review, v. 88, n. 2, Papers and Proceedings the hundred and tenth annual meeting of American Economic Association, may, 1998, p. 75-79. Disponível em: <www.jstor.org>. Acesso em: 05 jun. 2006. 